\title{
Probing the morphology and antiorganic fouling behaviour of the polyetherimide membrane modified with hydrophilic organic acids as additives
}

Raghavendra S. Hebbar ${ }^{\mathrm{a}}$, Arun M Isloor ${ }^{\mathrm{a} *}$ A.F. Ismail ${ }^{\mathrm{b}}$, Simon J. Shilton ${ }^{\mathrm{c}}$, Abdulrahman Obaid $^{\mathrm{d}}$ and Hoong-Kun Fun ${ }^{\mathrm{d}, \mathrm{e}}$

${ }^{a}$ Membrane Technology Laboratory, Chemistry Department, National Institute of Technology Karnataka, Surathkal, Mangalore 575 025, India

${ }^{b}$ Advanced Membrane Technology Research Center (AMTEC), Universiti Teknologi Malaysia, 81310 Skudai, Johor Bahru, MALAYSIA

${ }^{c}$ Department of Chemical and Process Engineering, University of Strathclyde, James Weir Building, 75 Montrose Street, Glasgow, G1 1XJ, Scotland

${ }^{d}$ Department of Pharmaceutical Chemistry, College of Pharmacy, King Saud University, P.O. Box. 2457 - Riyadh 11451, Kingdom of Saudi Arabia.

${ }^{e}$ X-ray Crystallography Unit, School of Physics, Universiti Sains Malaysia, Penang 11800, Malaysia

Abstract

A facile approach for the preparation of organic antifouling polymer membrane has been developed by using low molecular weight organic acids as additives. The presence of these additives in the membrane was analysed by FTIR spectroscopy. The properties of the modified membranes were investigated in terms of contact angle, water uptake capacity, SEM and AFM analysis. These additives exerted a strong impact on rheological properties of casting solution, thereby altering the membrane morphology, surface roughness, water flux and hydrophilicity of the membranes, as compared to the pristine Polyetherimide (PEI) membrane. The organic antifouling property of the modified membrane was analysed by filtering both Bovine Serum Albumin (BSA) and humic acid solutions. Results showed that, additives exhibited remarkable improvement in the antifouling property (FRR of $72 \%$.) and humic acid rejection up to $86 \%$. These outcomes offer new insight into the use of, cheaper and readily available organic acids as additives, compared to the traditional, synthetic polymer materials as additives in membrane preparation.

Key words : Organic acids, polyetherimide, humic acid, permeation, antifouling

* Corresponding author. Tel.: +91 824 2474000;

E-mail address: isloor@yahoo.com (A.M. Isloor) 


\section{Introduction,}

One of the most prevalent problems affecting the people throughout the globe is insufficient access to the clean water. Problems with water are probable to grow worse in the upcoming years because of the rapid growth of population, industrialization, global climate change and poor wastewater management. ${ }^{1-2}$ Since, it has gained much significance, the research work need to be concentrated on bringing forward a new and efficient water purifying method at lower cost with less energy. At the same time, it is necessary for minimizing the use of chemicals which impact on the environment. ${ }^{3}$ Membrane technology has gained vast application in the field of separation technology, especially in the water purification. ${ }^{4}$ As a result, preparation of hydrophilic, high flux and antifouling membranes is necessary to further expand the applications of membrane based separation process for water purification.

Polyetherimide (PEI) is a widely used membrane material due to its excellent mechanical and thermal properties. It has also a good film forming nature and chemically resistant to the wide range of $\mathrm{pH}^{5-6}$ It has been noticed that, membrane prepared from the pristine PEI is hydrophobic in nature. Due to which, membranes suffering from severe fouling because of adsorption or deposition of foulants, which reduces the water transport across the membrane and deteriorates properties of the membrane surfaces. ${ }^{7}$ Since the efficiency of ultrafiltration (UF) membrane processes for drinking water production is majorly dependent on the adverse fouling effects caused by natural organic materials (NOM's) present in the surface water. It is well known that, NOM's present in the water could easily react with chlorine to form highly carcinogenic by-products such as, trihalomethanes (THMs), haloacetic acids (HAAs) and other halogenated organics. ${ }^{8}$ Without an appropriate treatment process, direct exposure to these carcinogenic by-products could cause cancers, miscarriages and nervous system complications. Hence, effective removal of NOM from water has become a stimulating research topic in contemporary development of water purification technologies.

A major fraction of NOM's present in the surface or ground water is comprised of humic substances. ${ }^{9}$ Generally, humic acid (HA) makes up the main component of humic substance (Figure 1) and has thus been studied by many researchers as a model compound for natural organic matter in water. In the earlier report, Fan et al. stated that hydrophobic membranes were more susceptible to NOM's fouling than hydrophilic membranes during the filtration of NOM's. ${ }^{11}$ This was further substantiated by the work of Lee et al. in which by 
using membranes of approximately the same molecular weight cut-off (MWCO), the regenerated cellulose membrane was appeared to have lower fouling propensity compared to PES membrane. This was primarily due to the higher surface hydrophilicity. ${ }^{13}$ Among the approaches used to augment hydrophilicity of membrane material, the addition of hydrophilic additive into the casting solution is generally considered as one of the most convenient methods to create the impact.

\section{Figure-1}

From the literature, it was observed that, the presence of low molecular weight organic additives offers an effective and convenient way to alter the membrane performance with enhanced hydrophilicity, high permeability, antifouling and rejection properties. This finding was in line with work of Kim et al. revealed the effect of addition of additive on the pore size of the Polysulfone (PSF) membrane by the phase inversion method. The results showed that, $\gamma$-butyrolactone additive increased the pore size of the membrane because of its higher miscibility with the water than NMP. ${ }^{11}$ Kumar et al. prepared novel $N$ propylphosphonic chitosan derivative containing a terminal phosphonic acid functional group as an additive. The modified PSF membranes exhibited the improved hyrohilicity up to $58^{\circ}$ and antifouling properties with flux recovery ratio of $79 \%$ as compared to the pristine PSF membrane. ${ }^{12}$ Also Zhang et al. investigated the influence of formamide (FM) as an additive on the morphology and performance of the PEI membrane. The results showed that, dense skin layer of the membrane, strongly depends on the extent of FM in the casting solution and performance of the membrane was significantly increased. ${ }^{13}$ Further Ghaemi et al. extensively studied the effect of organic acids such as ascorbic acid, citric acid and maleic acid on the morphology and removal of xenobiotics. The contact angle measurements showed that, hydrophilicity of the PSF membrane increased considerably after the addition of additives. Also membrane with these acids exhibited higher water flux, permeation and rejection compared to polysulfone membrane. ${ }^{15}$ Chuang et al. reported the role of acetic acid (AA) as an additive in the formation of poly (vinyl alcohol) (PVA) membranes. The experimental results described that, the AA additive exerts strong impact on the morphology and other properties of the membrane. ${ }^{14}$ Rahimpour et al. studied the influence of 2hydroxyethylmethacrylate and acrylic acid additive on the structure and properties of the PSF membrane. ${ }^{16}$ The decreased surface roughness and pore size was observed for the modified 
membranes. Also significant improvement in the hyrophilicity, pure water flux and protein rejection was observed compared to the pristine PSF membrane.

Based on these observations, our current work is to emphasis on the influence of low molecular weight organic additive in the dope solution on the membrane morphology, hyrophilicity, permeation and antifouling properties. Ascorbic acid, citric acid and maleic acid comprising of different structure and acidic strengths were used as hydrophilic additives and influence of these additives on the rheological properties of casting solutions were investigated by viscosity measurement. The presence of these additives in the membrane was examined by FT-IR spectroscopy. The characteristics of the resultant membranes were investigated in terms of water uptake capacity, water contact angle measurement, surface roughness, morphological features and permeation properties. Further, the organic antifouling behaviour of membranes was investigated in detail by using Bovine Serum Albumin (BSA) and humic acid (HA) as model foulants.

\section{Materials and methods}

\subsection{Materials}

Polyetherimide (PEI) $(\mathrm{Mw}=35,000 \mathrm{Da})$ was purchased from Sigma Aldrich (India). The solvent N-methyl pyrrolidone (NMP) of analytical-grade purity was purchased from Merck, India. Bovine Serum Albumin (BSA) was obtained from Central Drug House (CDH), India. The humic acid was obtained from Himedia, India. The additives, ascorbic acid, citric acid and maleic acid were procured from Merck, India. The polyvinylpyrrolidone (PVP) was purchased from Sigma Aldrich, India.

\subsection{Preparation of Membranes}

The PEI membrane with various low molecular weight organic molecules as additives has been prepared according to the non-solvent induced Phase Separation method. ${ }^{17-18}$ For this purpose, desired ratio of PEI and PVP (pore forming agent) was dissolved in the desired volume of NMP at $60^{\circ} \mathrm{C}$. To this solution, calculated amount of different organic additives were separately added and magnetically stirred for $18 \mathrm{~h}$ at the same temperature. The obtained homogeneous solution was maintained for another $6 \mathrm{~h}$ in order to get rid of trapped air bubbles. The polymer solution was cast over a glass plate using a doctor's blade. Then it was gently immersed in the coagulation bath containing water as non-solvent. So obtained membrane was stored in deionised water for another $24 \mathrm{~h}$, to ensure the complete phase 
inversion. The obtained membrane was used for further analysis. Overviews of the experimental conditions were described in Table-1.

\section{Table-1}

\subsection{Membrane characterization}

\subsubsection{FTIR analysis}

The presence of low molecular weight organic additives in the membranes was analysed by FTIR studies. The FTIR spectra were recorded using Avatar 360 IR spectrophotometer in the range of $4000-400 \mathrm{~cm}^{-1}$. The changes in the characteristic peaks of spectra were discussed in results and discussion.

\subsubsection{Membrane morphology}

The variations in the surface and cross-sectional morphology of the membranes was investigated by JEOL JSM-6380LA Scanning Electron Microscope. For this purpose, the prepared membranes were fractured cryogenically using liquid nitrogen and then smeared with gold in order to obtain conductance.

\subsubsection{AFM analysis}

Atomic force microscopy (AFM) was used to examine the changes in the topography and surface roughness of the prepared membranes after the addition of low molecular weight organic acid as additives. Images of the dry samples were taken using annova SPM Atomic Force Microscope. A small piece of the membranes (almost $1 \mathrm{~cm}^{2}$ ) was cut and glued to a glass substrate. The image of membrane surfaces was obtained in a scan size of $10 \mu \mathrm{m} \times 10$ $\mu \mathrm{m}$ and tapping mode was used to measure the surface roughness.

\subsubsection{Viscosity measurement}

The Brookfield DV-III Ultra (USA) instrument was used to measure the viscosity of the casting solution. The viscosity was determined by using a cup/cone geometry at $90 / \mathrm{s}$ shear rate, $22 \mathrm{rpm}$ and $45^{\circ} \mathrm{C}$.

\subsubsection{Porosity}

Porosity of membrane was analysed by dry-wet weight method. ${ }^{19}$ The membrane soaked in distilled water was weighed after wiping the surface water with blotting paper. Then the wet membrane was placed in an air-circulating oven at $70^{\circ} \mathrm{C}$ for $24 \mathrm{~h}$ prior to 
measure the dry mass. From the two weights (the dry sample weight and the wet sample weight), the porosity of the membrane was calculated using equation (1).

$$
P(\%)=\frac{W_{w}-W_{d}}{\rho_{w} \times A \times \delta} \times 100
$$

Where ' $P$ ' is the porosity of the membrane, $W_{w}$ is the weight of wet sample $(\mathrm{g}), W_{d}$ is the weight of dry sample $(\mathrm{g}), \rho_{w}$ is the density of pure water $\left(0.998 \mathrm{~g} / \mathrm{cm}^{3}\right),{ }^{\prime} A^{\prime}$ is the area of membrane in wet state $\left(\mathrm{cm}^{2}\right)$ and ' $\delta^{\prime}$ is the thickness of membrane in wet state $(\mathrm{cm})$.

\subsubsection{Water uptake and contact angle measurement}

The water uptake study for the membrane was carried out according to the

literature. ${ }^{19}$ Briefly, the membrane $\left(1 \mathrm{~cm}^{2}\right)$ was immersed in in demineralized water for $24 \mathrm{~h}$ and weighed after wiping with blotting paper. Then the wet membrane was kept in a vacuum oven at $75^{\circ} \mathrm{C}$ for $25 \mathrm{~h}$ and the dry weight was measured. The percentage water content in the membrane was calculated using equation (2)

$$
\% \text { uptake }=\left(\frac{W_{w}-W_{d}}{W_{w}}\right) X 100
$$

Where $W_{w}$ and $W_{d}$ are the weights of the membranes after swelling for $24 \mathrm{~h}$ under wet and dry conditions respectively.

The hydrophilic property of the membrane was analysed by the water contact angle (WCA) measurement. It was measured using FTA-200 Dynamic contact angle analyser according to the sessile droplet method. In order to minimize the experimental errors, the WCA measurement of each sample was measured three times and average value was reported.

\subsubsection{Permeation properties}

The pure water flux (PWF) of all membranes was analysed by a self-fabricated dead end filtration cell at room temperature. The membranes with an effective area of $5 \mathrm{~cm}^{2}$ were dipped in distilled water for $24 \mathrm{~h}$ before commencing permeation experiment. Initially, each membrane was compacted at $0.4 \mathrm{MPa}$ for about $1 \mathrm{hr}$ and then it was reduced to $0.3 \mathrm{MPa}$ to obtain the pure water flux $\left(J_{w 1}, \mathrm{~L} / \mathrm{m}^{2} \mathrm{~h}\right)$. Then the flux was measured for every $10 \mathrm{~min}$ interval. The PWF, $J_{w}$ was determined using equation (3) 


$$
J_{w}=\frac{Q}{\Delta t A}
$$

Where $J_{w}$ is expressed in $\mathrm{L} / \mathrm{m}^{2} \mathrm{~h}$ and ' $Q^{\prime}$ is the amount of water collected for $\Delta t$ (h) time duration using a membrane of area ' $A$ ' $\left(\mathrm{m}^{2}\right)$.

\subsubsection{Antifouling properties}

The antifouling behaviour of all prepared membranes was analysed using the reported procedure as in literature. ${ }^{20}$ In brief, each membrane was subjected to compaction for an initial $30 \mathrm{~min}$ at $0.3 \mathrm{MPa}$. Then the pressure was reduced to $0.2 \mathrm{MPa}$ and PWF of the membrane was determined $J_{w 1}\left(\mathrm{~L} / \mathrm{m}^{2} \mathrm{~h}\right)$ at $0.2 \mathrm{MPa}$ TMP. The BSA solution was prepared with concentration of $0.8 \mathrm{~g} / \mathrm{L}$ and passed through the membrane for 80 minutes. After BSA filtration, membrane was thoroughly washed with distilled water for 20 minutes and again PWF, $J_{w 2}\left(\mathrm{~L} / \mathrm{m}^{2} \mathrm{~h}\right)$ was measured. Finally, the antifouling performance of the membrane was calculated in terms of flux recovery ratio (FRR) using the equation (4).

$$
\operatorname{FRR}(\%)=\left(\frac{J_{w 2}}{J_{w 1}}\right) \times 100
$$

Generally, higher FRR signifies a better antifouling behaviour of the membranes. Also, in order to examine the fouling processes, the following studies were carried out. To estimate the total protein fouling $\left(R_{t}\right)$ produced by the membrane after BSA filtration was calculated by the equation (5).

$$
R_{t}(\%)=\left(\frac{J_{w 1}-J_{p}}{J_{w 1}}\right) \times 100
$$

The flux loss caused from both reversible and irreversible protein fouling $\left(R_{r}\right.$ and $\left.R_{i r}\right)$, which were calculated using equation (6) and (7)

$$
\begin{aligned}
& R_{r}(\%)=\left(\frac{J_{w 2}-J_{p}}{J_{w 1}}\right) \times 100 \\
& R_{i r}(\%)=\left(\frac{J_{w 1}-J_{w 2}}{J_{w 1}}\right) \times 100
\end{aligned}
$$

\subsubsection{Humic acid rejection study}

The HA rejection behaviour of PEI membranes was carried out with the $5 \mathrm{mg} / \mathrm{L} \mathrm{HA}$ solution in the feed tank. In order to study the relative flux of the membrane, the PWF was 
evaluated before investigating the HA resistance behaviour of the membrane. The flux decline was measured in terms of relative fluxes.

The HA rejection efficiency of the membrane was tested by the filtration experiments. The concentration of HA solution in the feed tank and permeate solutions was measured by a UV-Vis spectrometer at a wavelength of $254 \mathrm{~nm}$. The HA rejection efficiency of the membrane was determined by using equation (8)

$$
\% \mathrm{R}=\left(1-\frac{\mathrm{C}_{\mathrm{p}}}{\mathrm{C}_{\mathrm{f}}}\right) \times 100
$$

Where $C_{f}$ and $C_{p}\left(\mathrm{mg} \mathrm{mL}^{-1}\right)$ are the concentration of the HA in the feed and permeate respectively.

\section{Results and discussion}

\subsection{ATR-IR spectroscopy}

The incorporation of low molecular weight organic acids as additives in the PEI membrane was confirmed by IR spectrum. The Figure 2 represents the IR spectrum of the PEI and modified PEI membranes. it was observed that, intensity of the IR bands at $1725 \mathrm{~cm}^{-}$ 1 and $1782 \mathrm{~cm}^{-1}$ related to $-\mathrm{C}=\mathrm{O}$ symmetric and asymmetric stretching respectively (characteristic imide group absorptions). The absorption peak at $1236 \mathrm{~cm}^{-1}$ corresponding to the aromatic ether linkage (C-O-C) of PEI. The membranes exhibited broad absorption peak around $3000-3600 \mathrm{~cm}^{-1}$ corresponding to the stretching of hydroxyl functional groups (-O-H) was obtained after the addition of these additives. This was due to, some of the additives remains in the casted polymer structure after the fabrication process.

\section{Figure-2}

\subsection{Water uptake capacity and contact angle}

The hydrophilic nature of the membranes could be analysed by their water uptake capacity and water contact angle measurements. The water uptake capacity of any membrane, primarily depends on two parameters, firstly on the number of hydrophilic sites present in membrane matrix and secondly, on the morphology i.e., the presence of macrovoids in the membrane sub-layer. ${ }^{21}$ It can be noticed from the results presented in the Table-2, all the membranes having a higher water uptake capacity compared to PMA-0 membrane. The PMA-3 membrane exhibited a maximum of $76 \%$, since citric acid offers more hydrophilicity than other additives. Also, it has been observed from the SEM images that, the presence of these acids in the casting solution showed increased macrovoid in the membrane sublayer. 
Due to this, the membrane can have more water molecules and thus increases the overall water uptake capacity.

The contact angle of the membranes was measured by the sessile drop method. The presence of these additive showed a decreasing trend of contact angle in the order of PMA-0 $>$ PMA-1> PMA-2 > PMA-3. In general, the smaller contact angle corresponding to the membrane surface with more hydrophilic nature. The pristine PEI membrane showed higher contact angle of $79^{\circ}$, whereas membrane with citric acid as an additive possessed contact angle of $68^{\circ}$. The significant change in the surface hydrophilicity of the membranes after the addition of these additives into the PEI casting solution can be attributed to the presence hydrophilic functional groups. The citric acid consists of three ionisable hydrogen atoms and it easily forms strong dipole interaction $\left(-\mathrm{COO}^{-\cdots \cdots} \mathrm{H}\right)$ with water molecules. This mechanism helps to hold the water molecule on the surface of the membranes. However, maleic acid consists of two and ascorbic acid having one ionisable hydrogen atoms respectively.

\section{Table-2}

\subsection{Rheological properties of the casting solutions}

The rheology of the casting solution having major influence on the exchange rate of non-solvent and solvent during the phase inversion and thus, it can be utilized as an important parameter to change the precipitation kinetics and consequently, the formation of resulting membrane morphology. ${ }^{22}$ The additive showed an increase in the viscosity of the casting solution (Table-2). The PAM-0 casting solution has shown viscosity of $270 \mathrm{mPas}$ and it was increased up to $650 \mathrm{mPas}$ for the $1 \mathrm{wt} \%$ citric acid in the dope solution. Since the higher viscosity of the casting solution decreases the diffusional exchange rate of the non-solvent (water) and solvent (NMP) during the membrane formation process. This can contribute to delayed demixing and consequent formation of thinner skin layer and larger finger-like pores (or macrovoids) in the sub-layer.

\section{4 porosity of the membranes}

Table-2 indicates an effect of these hydrophilic additives on the porosity of the membranes. The results revealed that, all modified membranes exhibited higher porosity compared to the PAM-0 membrane. It can be found that, modified membrane exhibited enhanced porosity of 22- $34 \%$ compared to the PAM-0 membrane. Moreover, membrane with $1 \mathrm{wt} \%$ citric acid has shown higher porosity (i.e higher pore density) among other two additives. The changes in the porosity of the membranes were explained by the following 
reasons: 1 . The addition of these additives showed an increase in the viscosity of the dope solution (table-2). Which delays the exchange between solvent and non-solvent during the phase inversion process. In highly viscous dope solution, solvent's (NMP) outward diffusion from the casting film is preferred over non-solvent's (water) inward diffusion because of its barrier effect against non-solvent. Since delayed demixing on the surface region of the casting film caused the formation of a dense top layer with higher porosity. 2. A portion of PVP (invariable additive) was leached out of the casting film during the phase separation and acted as pore forming agent. This could be another reason for enhanced porosity of the membranes.

\subsection{Effect of additive on morphology of the membrane}

The SEM was employed to study the morphological changes in the membranes, which play a significant role in the performance and selectivity of the membranes. During membrane preparation, casted polymer film was gently immersed in a coagulation bath containing water as non-solvent. Upon immersion, non-solvent (water) enthused inward into the cast film from the coagulation bath. This enforced a remarkable change in the driving force across the cast film. At the same time, the polymer rich phase allowed water molecule (non -solvent) to equilibrate between the internal and external phases of polymer film before significant outward diffusion of NMP (solvent) molecules. Since, the influx of water molecule was predominantly high as compared to the out flux of NMP. This is because of the large diffusion coefficient of tiny water molecules compared to that of the much bulkier organic solvent molecule. ${ }^{23-24}$ On the other hand, the solvent (NMP) having strong affinity towards water molecule, so that they miscible each other instantaneously. These phenomena resulted in the formation of asymmetric membranes. From the Figure 3, it is clear that, all the prepared membranes have typical asymmetric structures, which consist of the thin skin layer and the porous sub layer. Further, we studied the effect of low molecular weight organic additives such as citric acid, ascorbic acid and maleic acid, which has a different structure and strength on PEI membrane morphology. Generally, these additives are used to act as a non-solvent against the base polymer because, skin and bottom layer morphology of the membranes are largely influenced by the rate of coagulation of the casting solution. The changes in the morphology with different additives discussed below.

\subsubsection{Citric acid}

The citric acid, which is a polycarboxylic acid was used as one of the additive in PEI membrane preparation. From the Figure 3 (d), it can be observed that, formation of 
asymmetric structure with thinner skin layer thickness compared to neat PEI membranes. The induced changes in membrane morphology may be due to the interaction between components in the casting solution. The addition of citric acid into the casting solution may result in the formation of the secondary intermolecular force of interaction with the polymer chains (Figure 4). The different type of secondary forces such as hydrogen bonding, dipole interaction and dispersion forces reduced interaction among polymer chains. In addition, due to the hydrophilic nature of the citric acid there is a possibility for the formation of hydrogen bonds with solvent (NMP) molecule also. ${ }^{15}$ The both phenomena exhibited decreased outflow rate of solvent (NMP) and increased inflow rate of non-solvent (water), which resulted in delayed demixing in the coagulation bath. Therefore, the growth of the skin layer is reduced and formation of finger-like pores (or macrovoid) in the sub layer is improved.

\section{Figure-3}

\section{Figure-4}

\subsubsection{Ascorbic acid}

The ascorbic acid is a polyhydroxy acid used as another hydrophilic additive in the preparation of PEI casting solutions. The change in the morphological features like decline of skin layer thickness and formation of macrovoids in the sub-layer can be described in the same way as in the case of citric acid. (a) Decrease in the interactions between polymer chains due to the formation of the secondary intermolecular force of interaction between ascorbic acid and polymer chains. (b) Increase in the inflow of water molecule (non-solvent) and decrease in the solvent (NMP) outflow because of the hydrophilic nature of ascorbic acid (c). Also, there may be formation of hydrogen bonding between solvent and ascorbic acid. ${ }^{25}$ Eventually, the rate of demixing affects the membrane formation with a thinner top-layer thickness and formation of macro-voids in the sub-layer compared to the pristine PEI membrane

\subsubsection{Maleic acid}

The maleic acid is a dicarboxylic acid employed as another additive in the preparation of PEI casting solutions. The change in the morphological features compared to the neat PEI membrane can be explained similarly as above. Since the addition of maleic acid produces instability in the thermodynamic equilibrium of the system. ${ }^{25}$ Subsequently, the rate of demixing of solvent and non-solvent changes and resulting membrane with thinner top skin layer and formation of finger-like pores in the sub-layer. 


\subsection{AFM analyses of membrane}

AFM analysis was carried out, to further explore the influence of these additives on surface topology and roughness parameters of the PEI membrane. Figure 5 illustrates the representative two and three dimensional topological images of all prepared membranes. From the images, the organic acids having a strong influence on the surface morphology of the membranes. The surface roughness is one of the most important parameter as it has a strong impact on fouling behaviour and also on the local mass transfer. ${ }^{26}$ The results for roughness parameters, for PEI and modified membranes are presented in Table 3. All the membrane showed lower surface roughness as compared to the pristine PEI membrane i.e PAM-0. The maximum mean roughness $(\mathrm{Ra})$ and route mean square roughness $(\mathrm{Rq})$ value showed by PAM-0 membrane was $11.5 \mathrm{~nm}$ and $14.3 \mathrm{~nm}$ respectively. The membrane with citric acid as additive showed decrease in mean roughness around $48 \%$ with the maximum feature heights (Rmax) of $61.5 \mathrm{~nm}$ compared to other membranes. This observation is particularly important since smoother surface shows the less adsorption of organic molecules to reduce the organic fouling.

\section{Figure-5}

\section{Table-3}

\subsection{Water permeability}

The filtration experiments have been conducted to investigate the permeability and antifouling property of the membranes. The important parameters like, water uptake capacity, hydrophilicity and morphological properties decide the performance of the membranes. Figure 6 represents the PWF of the membranes. The pristine PEI membrane showed a minimum of $133 \mathrm{~L} \mathrm{~m}^{-2} \mathrm{~h}^{-1}$ and membranes with citric acid as additive showed maximum PWF of $242 \mathrm{~L} \mathrm{~m}^{-2} \mathrm{~h}^{-1}$. The remarkable change in the performance of the membranes after the addition of organic acids as additives induced changes on the hydrophilicity and permeation properties of the membranes. The citric and malic acids having three and two carboxylic acid functional groups which impart the negative charge of the membranes. The carbonyl groups bonded to $-\mathrm{OH}$ in carboxylic acid moieties has electrophilic character. Since carboxylic acids undergo dissociation easily and form the carboxylate anion. Ascorbic acid molecules are not able to properly ionize their - $\mathrm{OH}$ functional groups because they do not have linked carbonyl groups. But it contains a number of hydroxyl groups and one ionisable hydrogen atom in its structure, which induce the hydrophilicity to the membranes.

\section{Figure-6}




\subsection{Antifouling performance against BSA}

The most detrimental problem with membrane technology is fouling, which hampered the long term use of the membrane. The fouling is caused by the deposition or adsorption of particles, proteins, colloids, salts, macromolecules, etc., at the membrane surface or inside the pores. ${ }^{26}$ It is well known that, an increase in hydrophilicity offers the enhanced fouling resistance of the membrane. Since strongly bound water molecules that prevent protein molecules from binding to surfaces. The contact angle and permeation results are direct evidences for the increased hydrophilicity of modified membrane as compared to the neat PEI membrane. As expected, the modified membranes showed the better antifouling property. BSA molecules have an isoelectric point of 4.9 , therefore, BSA exhibit negative charge in the neutral solution. ${ }^{27}$ The membrane surface is also negatively charged due to the presence of polycarboxylic acid or dicarboxylic acid or polyhydroxy acid of the additives on membrane surface. This resulted in a strong electrostatic repulsion force between negatively charged BSA molecules and membrane surface to reduce the fouling.

The antifouling properties of the membranes with and without additives (organic acids) were investigated by measuring the pure water flux recovery after membrane fouled by the $800 \mathrm{ppm}$ of BSA solution. Figure 7 shows the pure water flux before, during and after BSA filtration. Water fluxes of the fouled membranes were measured after thorough washing with distilled water. The flux recovery ratio (FRR) of the prepared membranes is described in Table-4. The higher FRR value indicates a better antifouling property for the membrane. The pristine membrane exhibit lower flux recovery ratio of $21.4 \%$ and membrane with citric acid as additive showed maximum FRR of $71.6 \%$. This specifies the high antifouling property of the modified membranes induced by the low molecular weight organic acids. The observed trend of FRR is matched by hydrophilicity of the membranes (Figure 8). Hydrophilic surface can adsorb water molecules and form a water layer, which retards the adsorption of protein and other fouling agents. ${ }^{28}$

\section{Figure-7}

\section{Figure-8}

In general, the membrane fouling can be categorized as hydraulically irreversible and reversible. In hydraulically irreversible fouling, the fouling agents are strongly attached to the membrane and it can only be cleaned by chemical treatment. In case of hydraulically reversible fouling, the foulants are loosely bound to the membrane and it can easily be 
removed by backwashing. ${ }^{29-30}$ The Table-4 represents the hydraulically reversible $\left(R_{r}\right)$, hydraulically irreversible fouling ratio $\left(R_{i r}\right)$ and total fouling ratio $\left(R_{t}\right)$ for the membranes. From the results, it was clear that, all the modified membranes exhibited higher hydraulic reversibility in the order of PMA-3 > PMA-1 $>$ PMA-2 $>$ PMA-0. The hydraulic reversible fouling ratio of the membrane was considerably increased from $14.5 \%$ for the pristine membrane to $65.7 \%$ for the membrane with citric acid as the additive. These results demonstrate that, membrane with organic acids as additives show a remarkable change in the pure water flux, hydrophilicity and antifouling property.

\section{Table-4}

\subsection{Antifouling performances against HA}

To further investigate the HA rejection and antifouling property of the prepared membranes, the filtration experiments were carried out at $0.2 \mathrm{MPa}$ TMP with $5 \mathrm{mg} / \mathrm{L}$ initial concentration in the feed tank. The Figure 9 represents the relative fluxes of the membranes. It clearly showed that, the rate and extent of is fouling reduced significantly after the addition of additives (Figure 10). The rapid flux declined was observed at the beginning of each filtration experiment. The adsorption of HA is considered as the first step in membrane fouling and is strongly be influenced by on the physico-chemical properties of both membranes and foulants, especially the affinity of foulants towards the membrane material. ${ }^{31}$ A maximum in the resistance against fouling was observed for the PAM-3 membrane with HA rejection up to $84.7 \%$ (Figure 11). This is corresponding to the low contact angle (higher hydrophilicity) and other surface parameters. Considering that, here fouling is dominated by the adsorption of HA on the membrane surface. Since these additives impart the negative charge to the membrane, reduce adsorption of HA on the membrane surface due to the electrostatic repulsion between HA molecules and the membrane surface. ${ }^{32}$ Therefore, it is important to prepare the membrane with improved hydrophilicity and less roughness to improve antifouling ability and performance of the membrane.

\section{Figure-9}

\section{Figure-10}

\section{Figure-11}

\section{Conclusion}

The presence of a small quantity of low molecular weight organic acids in the casting solution imparts a strong influence on the morphology and antifouling properties of 
polyetherimide membrane. The rheology of the casting solution was changed dramatically after addition of additive and highly influenced membrane morphological features. The modified membrane showed significantly thinner skin-layer, formation of macro-voids in the sublayer and smoother surface compared to the pristine polyetherimide membrane. The water uptake capacity and water contact angle measurements confirmed the enhanced hydrophilicity of the membranes for all of the organic acid additives. The permeation experiments showed enhanced water flux of $242.3 \mathrm{~L} \mathrm{~m}^{-2} \mathrm{~h}^{-1}$ with flux recovery ratio up to 72 $\%$ for PAM-3 membrane. The humic acid rejection study showed that modified membrane having rejection efficacy up to $86 \%$. Overall, the performance of the membranes revealed that, prepared membranes with citric acid offered a higher efficiency compared to maleic acid and ascorbic acid.

Acknowledgements AMI thank the Director, National Institute of Technology Karnataka, Surathkal, India for providing the research facilities and encouragements. The authors also thank Prof K. Narayan Prabhu and Prof K. Rajendra Udupa of Metallurgical and Materials Engineering Department, of NITK Surathkal, India for the contact angle measurements and SEM facility. The authors extend their appreciation to The Deanship of Scientific Research at King Saud University for funding the work through research group project no. RGP-VPP207.

\section{References}

1. R. L. McGinnis and M. Elimelech, Environ. Sci. Technol., 2008, 42, 8625-8629

2. M. A. Shannon, P. W. Bohn, M. Elimelech, J. G. Georgiadis, B. J. Marinas and A. M. Mayes, Nature, 2008, 452, 301-310.

3. G. M. Geise, H. S. Lee, D. J. Miller, B. D. Freeman, J. E. McGrath and D. R. Paul, J. Polym. Sci., Part B: Polym. Phys., 2010, 48, 1685-1718.

4. R. Kumar, A. M. Isloor, A. F. Ismail and T. Matsuura, Desalination, 2013, 318, 1-8.

5. J. Chen, J. Li, X. Zhan, X. Han and C. Chen, Front. Chem. Eng. Chin., 2010, 4, 300306.

6. R. S. Hebbar, A. M. Isloor and A. Ismail, RSC Advances, 2014, 4, 55773-55780.

7. W. Chinpa, D. Quémener, E. Bèche, R. Jiraratananon and A. Deratani, J. Membr. Sci., 2010, 365, 89-97.

8. L.-L. Hwang, H.-H. Tseng and J.-C. Chen, J. Membr. Sci., 2011, 384, 72-81.

9. A. Rahimpour and S. S. Madaeni, J. Membr. Sci., 2010, 360, 371-379.

10. J. Parsons, Soil Sci., 1983, 135, 129-130. 
11. I. C. Kim and K. H. Lee, J. Appl. Polym. Sci., 2003, 89, 2562-2566.

12. R. Kumar, A. M. Isloor, A. F. Ismail and T. Matsuura, J. Membr. Sci., 2013, 440, 140-147.

13. L. Zhang, G. He, W. Zhao, M. Tan and X. Li, Sep. Purif. Technol., 2010, 73, 188-193.

14. W.-Y. Chuang, T.-H. Young and W.-Y. Chiu, J. Membr. Sci., 2000, 172, 241-251.

15. N. Ghaemi, S. S. Madaeni, A. Alizadeh, P. Daraei, M. M. S. Badieh, M. Falsafi and V. Vatanpour, Sep. Purif. Technol., 2012, 96, 214-228.

16. A. Rahimpour, S. S. Madaeni and Y. Mansourpanah, J. Membr. Sci., 2010, 364, 380388.

17. V. R. Pereira, A. M. Isloor, A. Al Ahmed and A. Ismail, New J. Chem., 2015, 39, 703-712.

18. R. S. Hebbar, A. M. Isloor and A. Ismail, RSC Advances, 2014, 4, 47240-47248.

19. Y.-H. Wu, H. B. Park, T. Kai, B. D. Freeman and D. S. Kalika, J. Membr. Sci., 2010, $347,197-208$

20. R. Kumar, A. M. Isloor, A. Ismail, S. A. Rashid and T. Matsuura, RSC Advances, 2013, 3, 7855-7861.

21. B. M. Ganesh, A. M. Isloor and A. F. Ismail, Desalination, 2013, 313, 199-207.

22. E. Saljoughi and T. Mohammadi, Desalination, 2009, 249, 850-854.

23. S. Rajesh, A. Jayalakshmi, S. Senthilkumar, H. S. H. Sankar and D. R. Mohan, Ind. Eng. Chem. Res., 2011, 50, 14016-14029.

24. Z. Li, J. Ren, A. G. Fane, D. F. Li and F.-S. Wong, J. Membr. Sci., 2006, 279, 601607.

25. D. Wandera, S. R. Wickramasinghe and S. M. Husson, J. Membr. Sci., 2011, 373, $178-188$.

26. D. Rana and T. Matsuura, Chem. Rev. (Washington, DC, U. S.), 2010, 110, 24482471.

27. S. Boributh, A. Chanachai and R. Jiraratananon, J. Membr. Sci., 2009, 342, 97-104.

28. Z. Xu, J. Zhang, M. Shan, Y. Li, B. Li, J. Niu, B. Zhou and X. Qian, J. Membr. Sci., 2014, 458, 1-13.

29. S. Zinadini, A. A. Zinatizadeh, M. Rahimi, V. Vatanpour and H. Zangeneh, J. Membr. Sci., 2014, 453, 292-301.

30. J.-H. Jiang, L.-P. Zhu, H.-T. Zhang, B.-K. Zhu and Y.-Y. Xu, J. Membr. Sci., 2014, 457, 73-81.

31. L.-L. Hwang, J.-C. Chen and M.-Y. Wey, Desalination, 2013, 313, 166-175. 
32. X. Li, X. Fang, R. Pang, J. Li, X. Sun, J. Shen, W. Han and L. Wang, J. Membr. Sci., 2014, 467, 226-235.

\section{LIST OF CONTENTS}

\section{Figures}

Figure 1 : Structural model of humic acid ${ }^{10}$

Figure 2: FT-IR spectra of prepared membranes

Figure 3 : The cross sectional and magnified cross sectional SEM images of a, A) PMA-0, b, B) PMA-1, c, C) PMA-2 and d, D) PMA-3 membrane

Figure 4 : Schematic representation of hydrogen bond interaction between the polymer and organic acid

Figure 5 : Two and three dimensional AFM surface images of a, A) PMA-0, b, B) PMA-1, c, C) PMA-2 and d, D) PMA-3 membrane

Figure 6 : Pure water flux of the membranes with $0.2 \mathrm{MPa}$ pressure

Figure 7 : Flux variation of membranes during three different conditions with $0.2 \mathrm{MPa}$ pressure. PWF for 80 min, BSA flux $(\mathrm{pH}=7 \pm 0.2) 80 \mathrm{~min}$ and water flux for $80 \mathrm{~min}$ after 20 min washing with distilled water

Figure 8: The contact angle and flux recovery ratio of the prepared membranes

Figure 9 : Flux ratio during the HA solution filtration

Figure 10 : The HA rejection by prepared membranes

Figure 11 : Photographic image of (a) feed HA solution and b,c and d are the permeate of PMA-1, PMA-2 and PMA-3 membranes

\section{Tables}

Table-1 Composition of casting solution

Table-2 The properties of the membranes

Table- 3 The roughness parameters of the membranes

Table-4 Filtration and antifouling performances of the membranes 


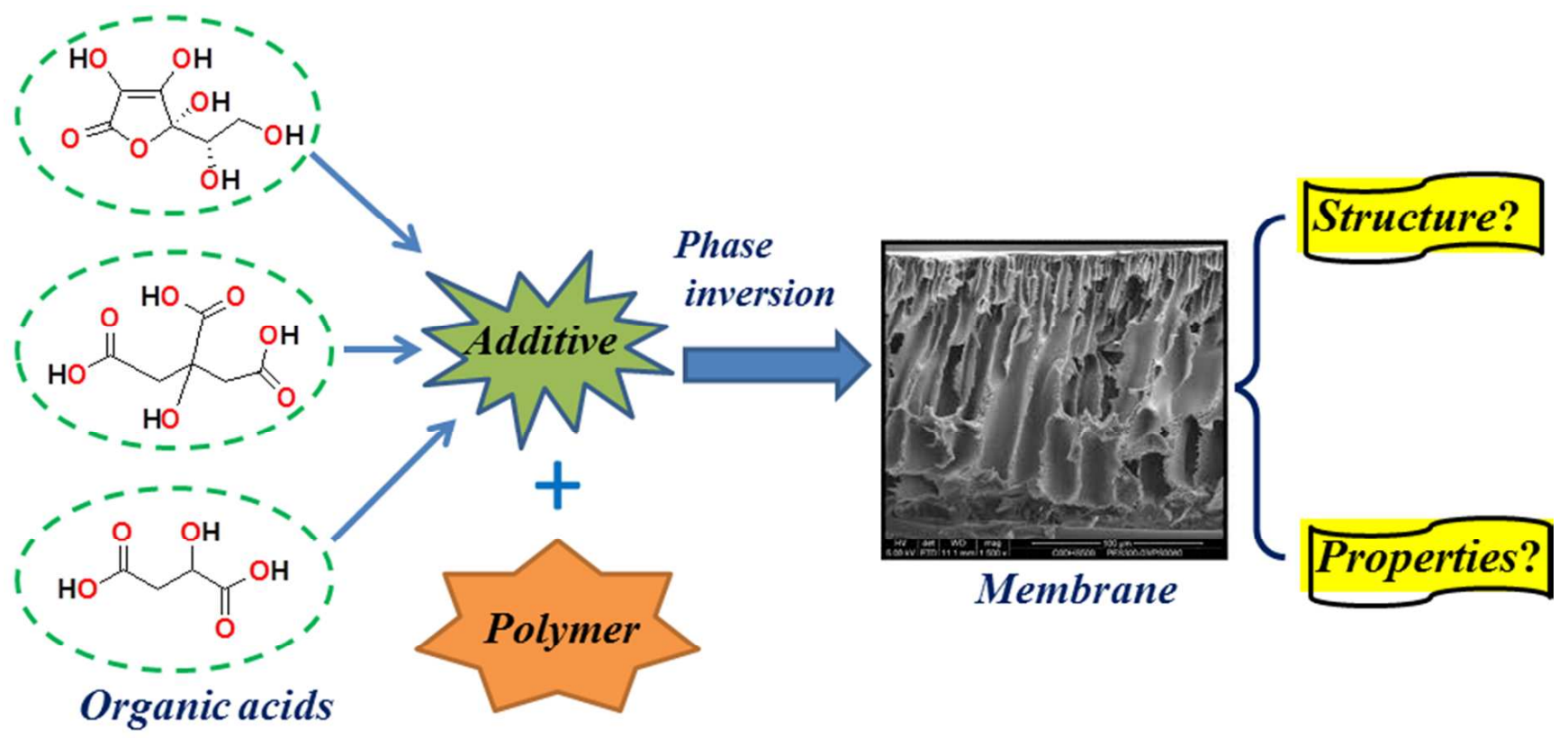

Polyetherimide based membrane was modified with various hydrophilic organic acids as additives. The results showed that the additives exhibited remarkable improvement in the antifouling property (FRR of $72 \%$.) and humic acid rejection up to $86 \%$. 

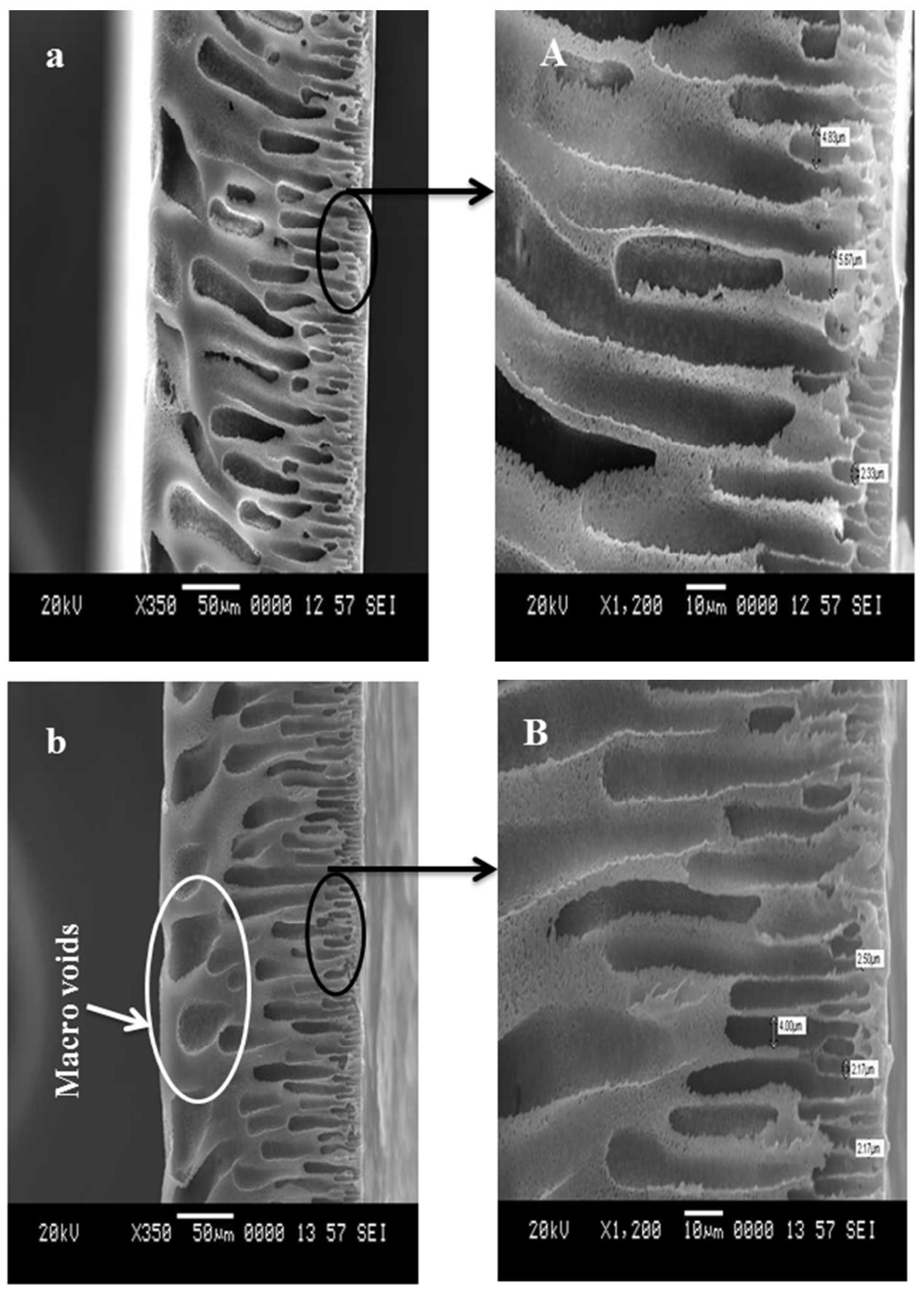

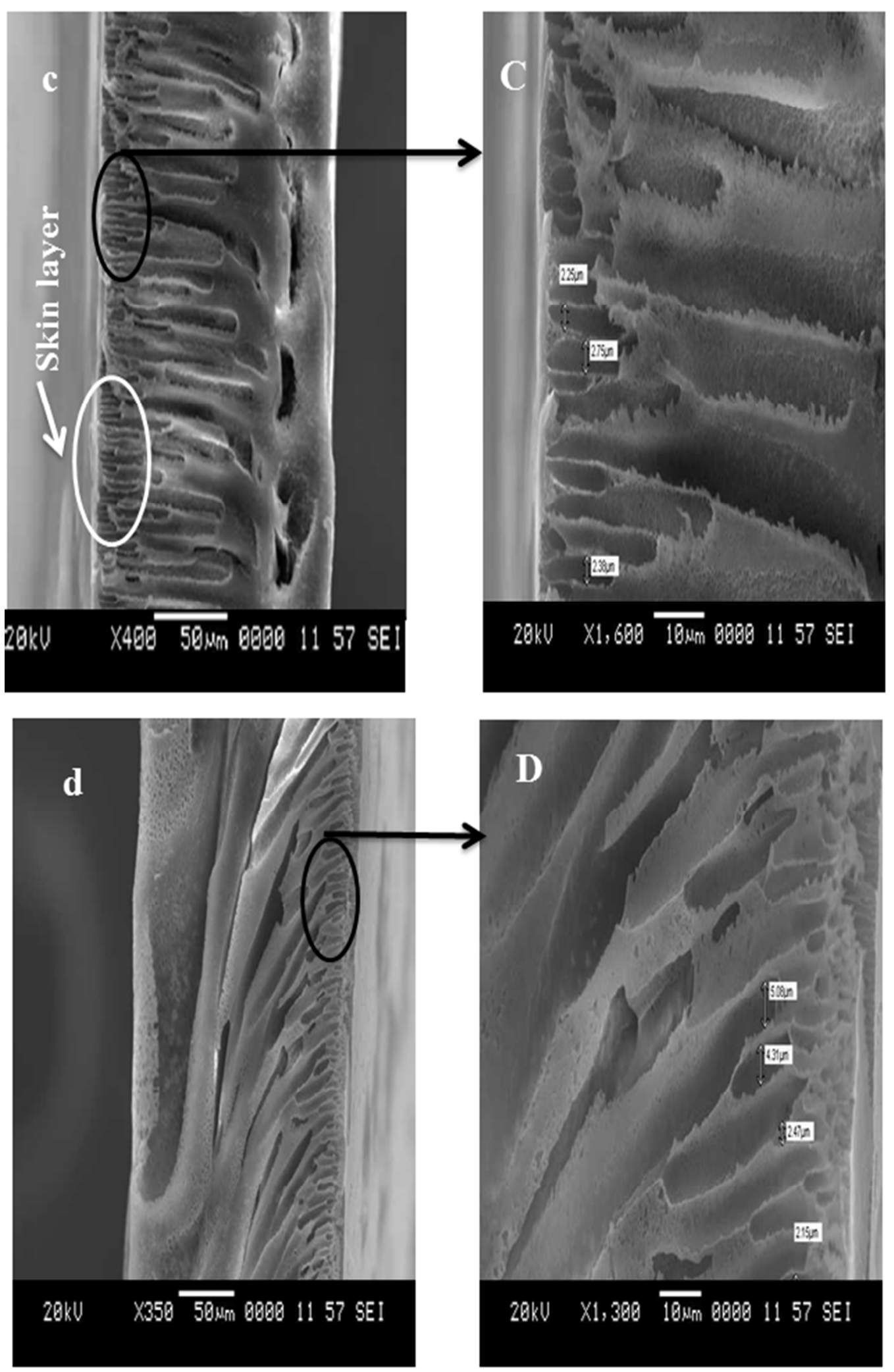

Figure 3 : The cross sectional and magnified cross sectional SEM images of a, A) PMA-0, b, B) PMA-1, c, C) PMA-2 and d, D) PMA-3 membrane 


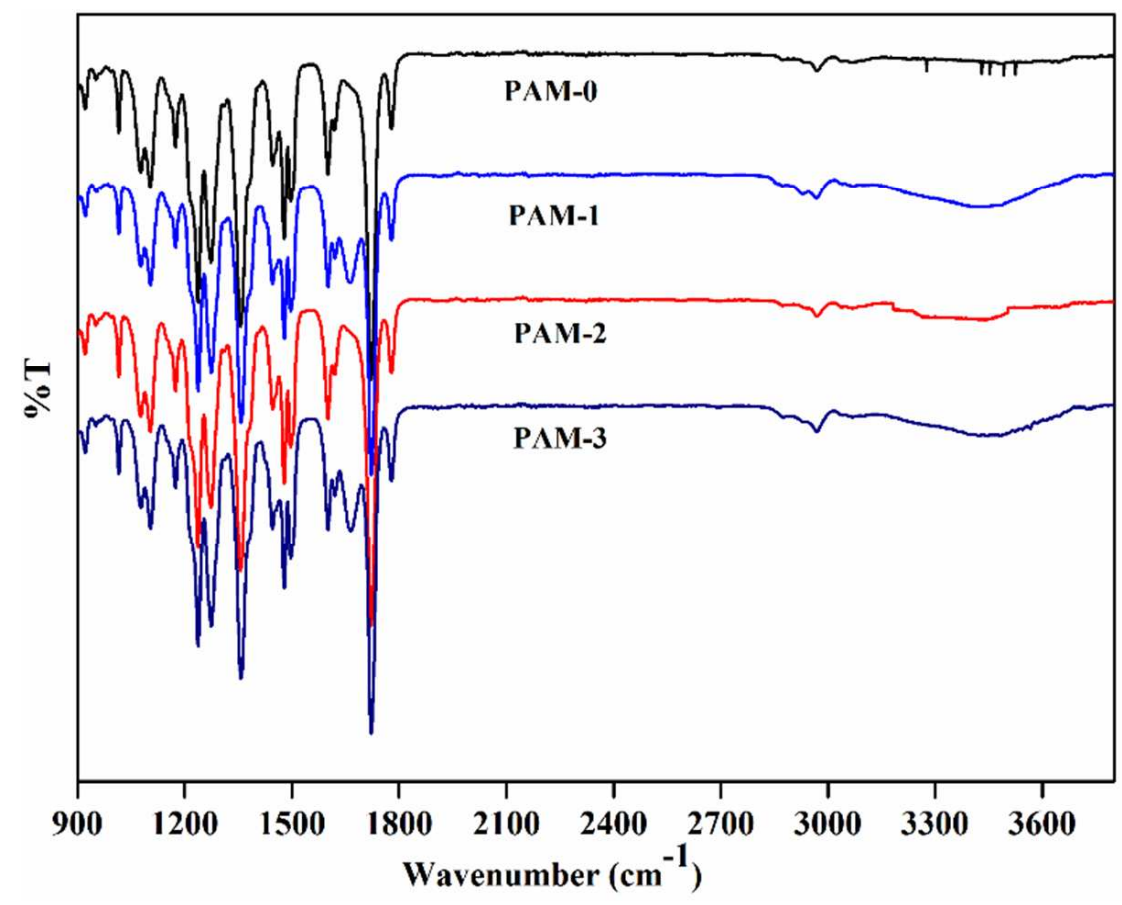

Figure 2 : FT-IR spectra of prepared membranes 


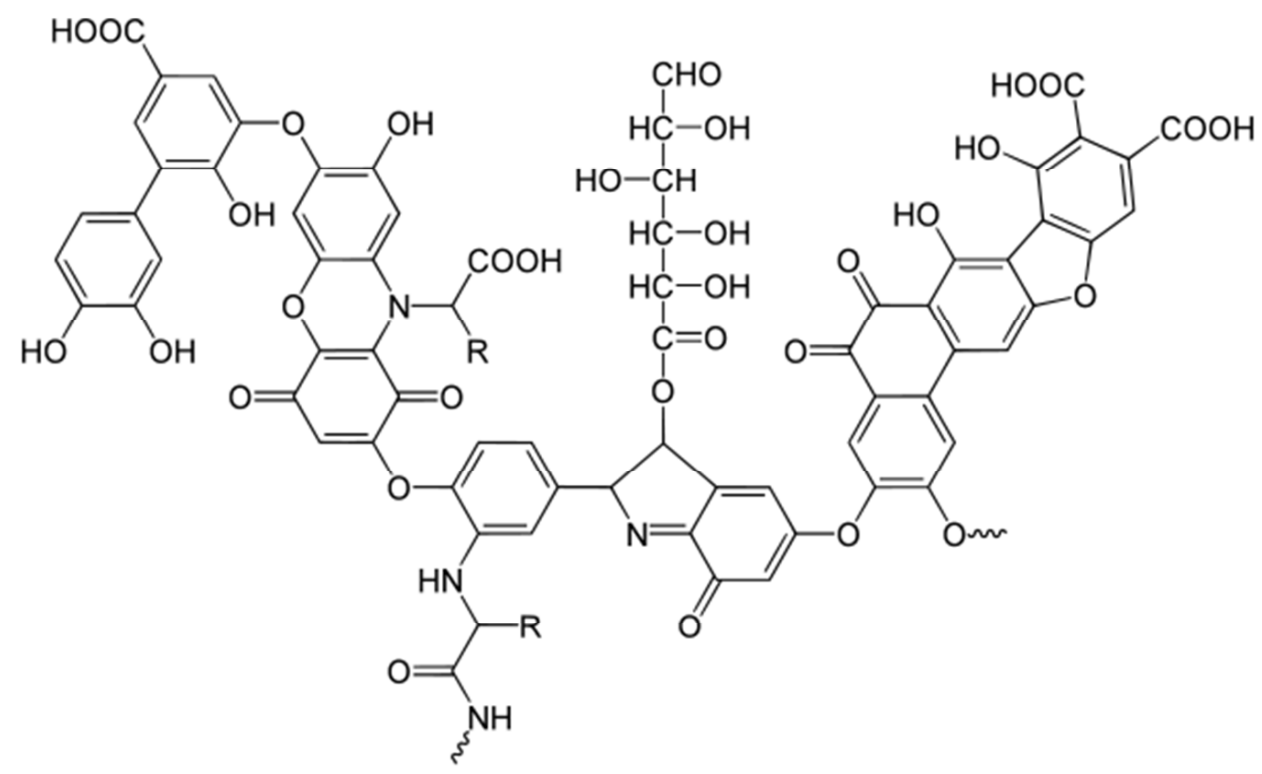

Figure 1 : Structural model of humic acid [10] 
PEI $\left|\|_{0}\right|^{s^{5}}+$

PEI

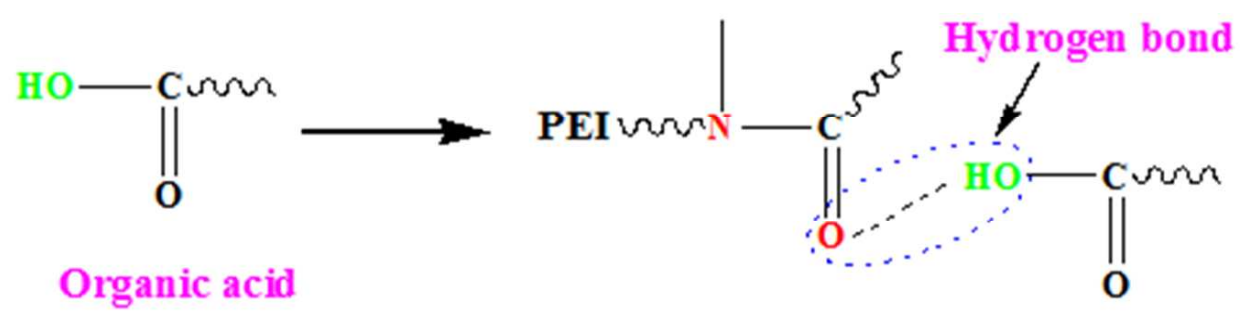

Figure 4 : Schematic representation of hydrogen bond interaction between the polymer and organic acid 

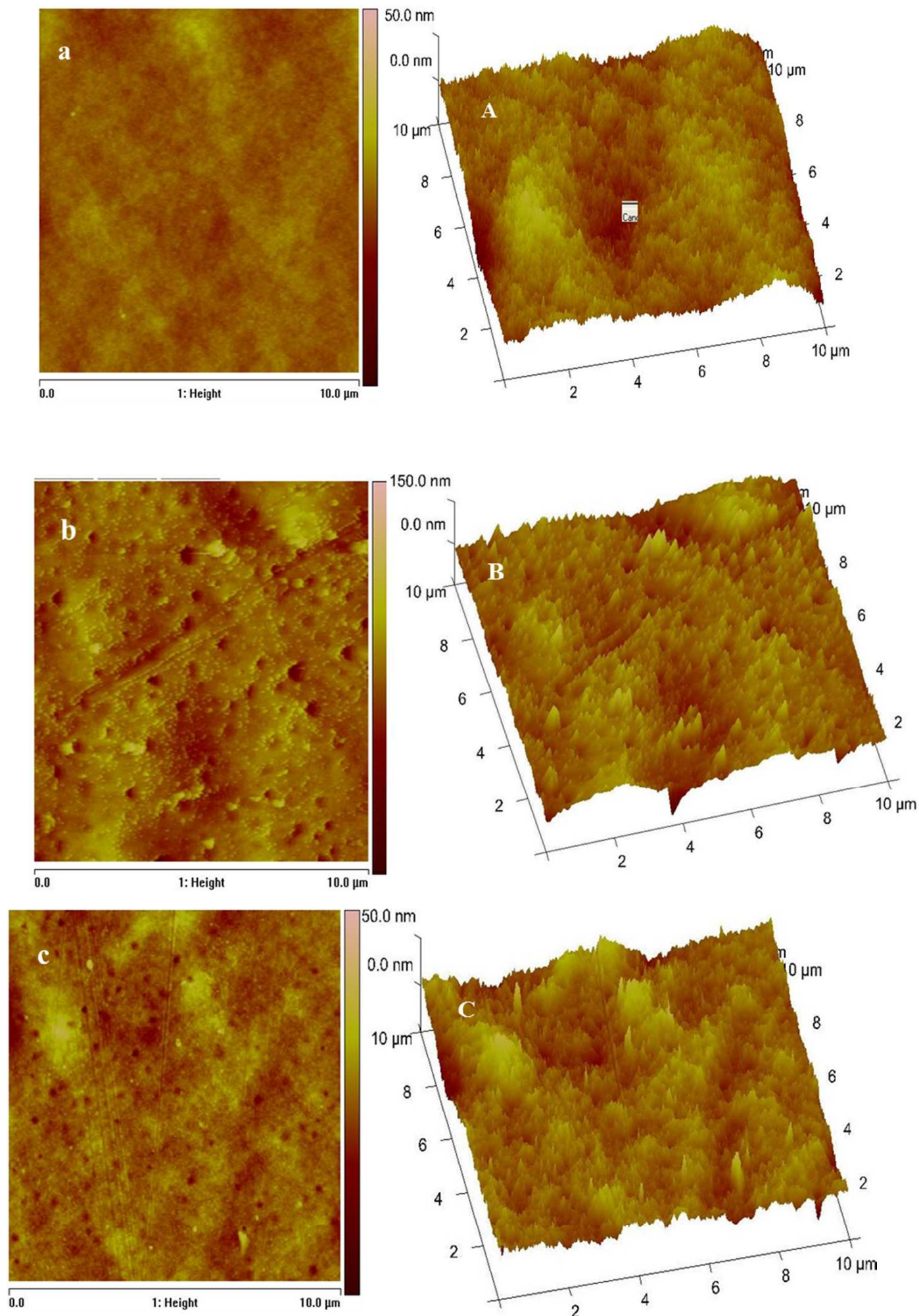


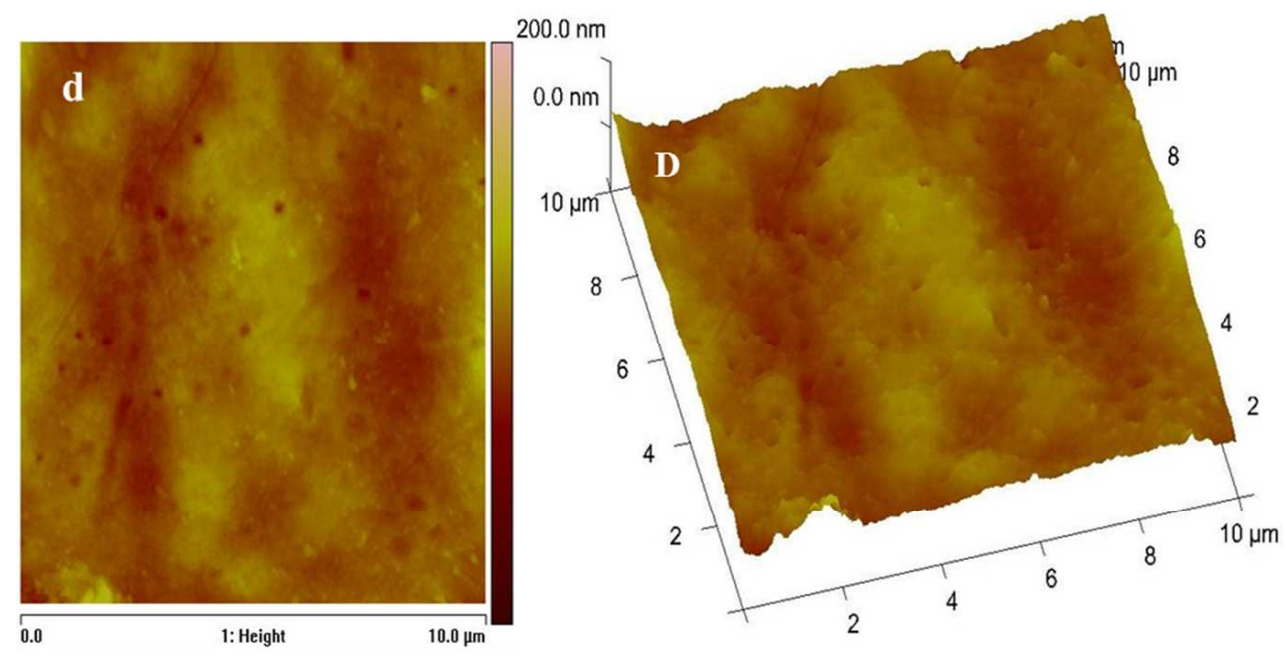

Figure 5 : Two and three dimensional AFM surface images of a, A) PMA-0, b, B) PMA-1, c, C) PMA-2 and d, D) PMA-3 membrane 


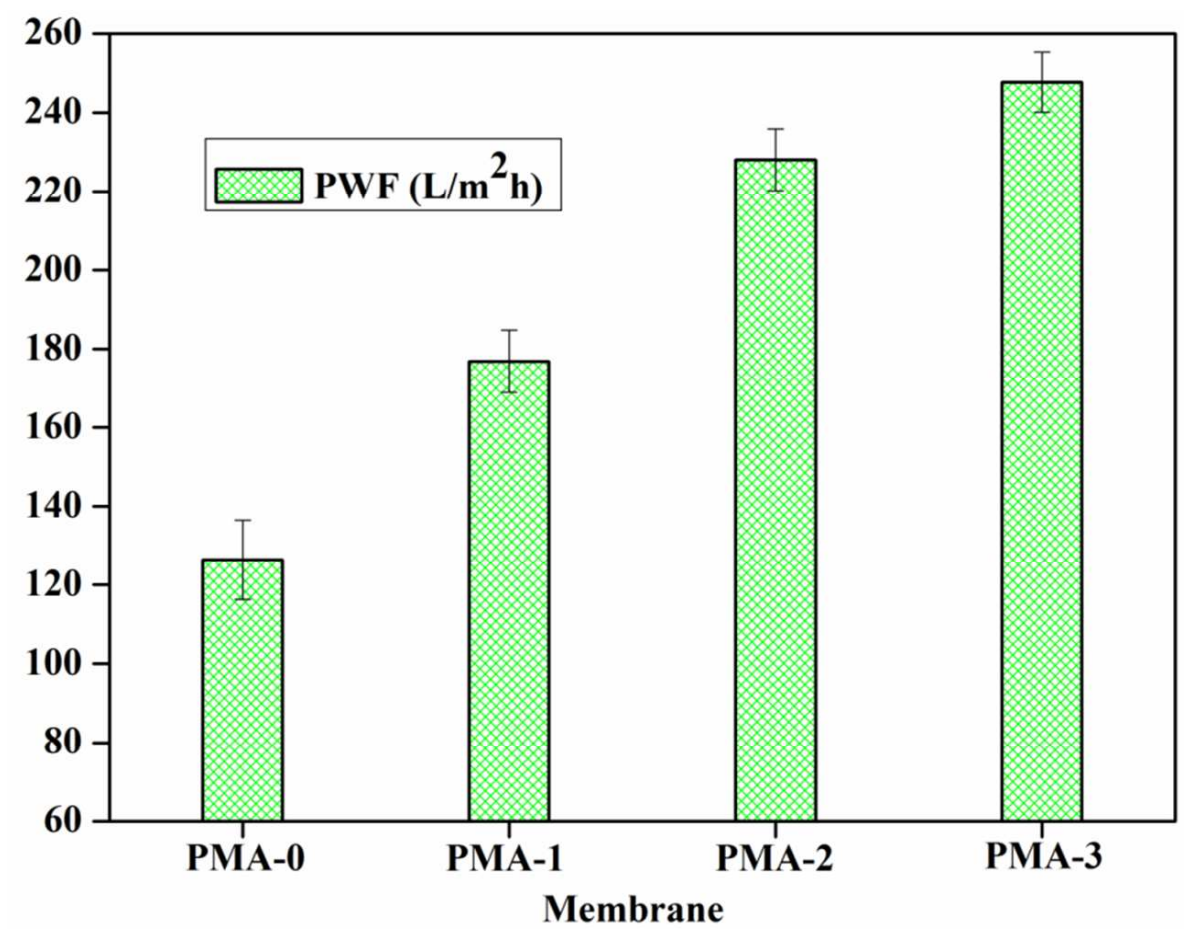

Figure 6 : Pure water flux of the membranes with $0.3 \mathrm{MPa}$ pressure 


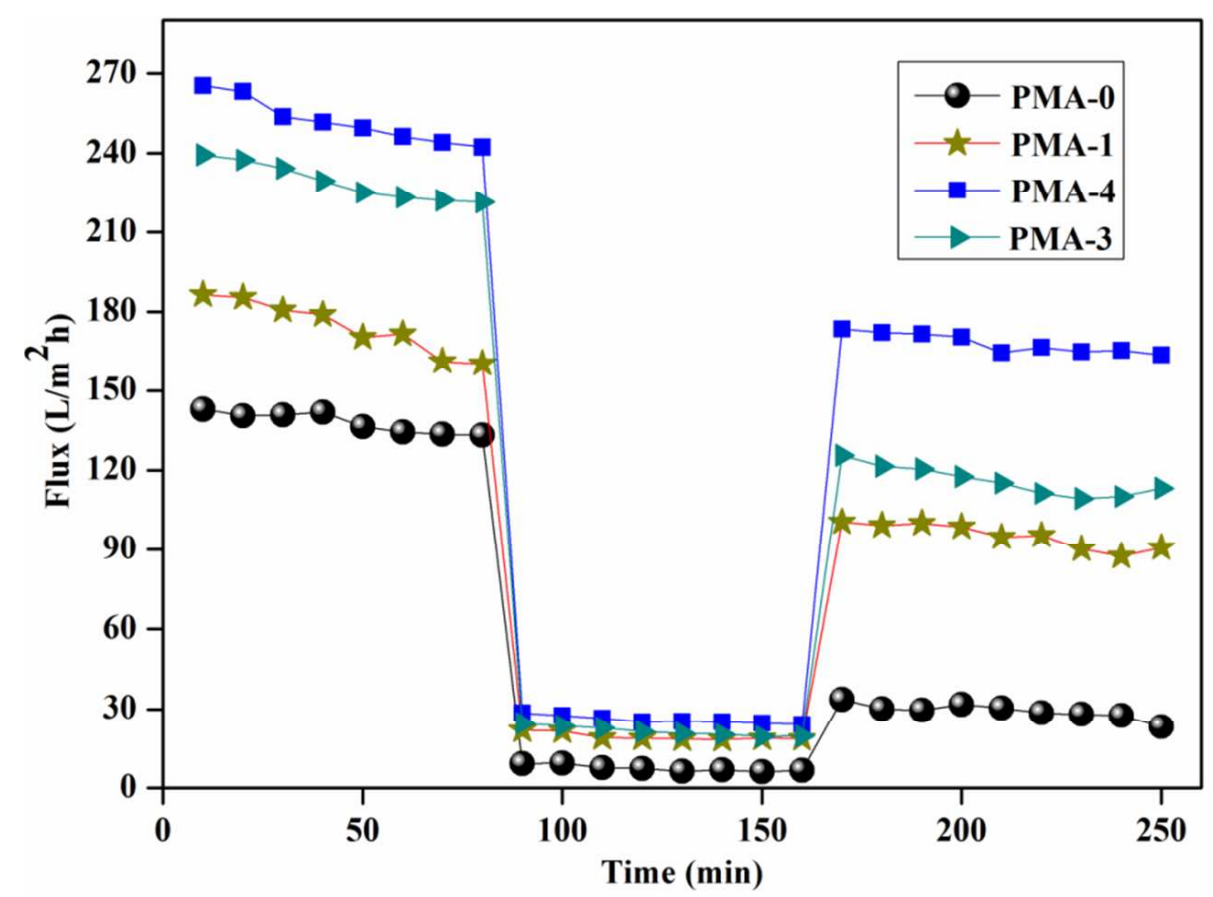

Figure 7 : Flux variation of membranes during three different conditions with $0.2 \mathrm{MPa}$ pressure. PWF for 80 min, BSA flux ( $\mathrm{pH}=7 \pm 0.2) 80 \mathrm{~min}$ and water flux for $80 \mathrm{~min}$ after 20 min washing with distilled water. 


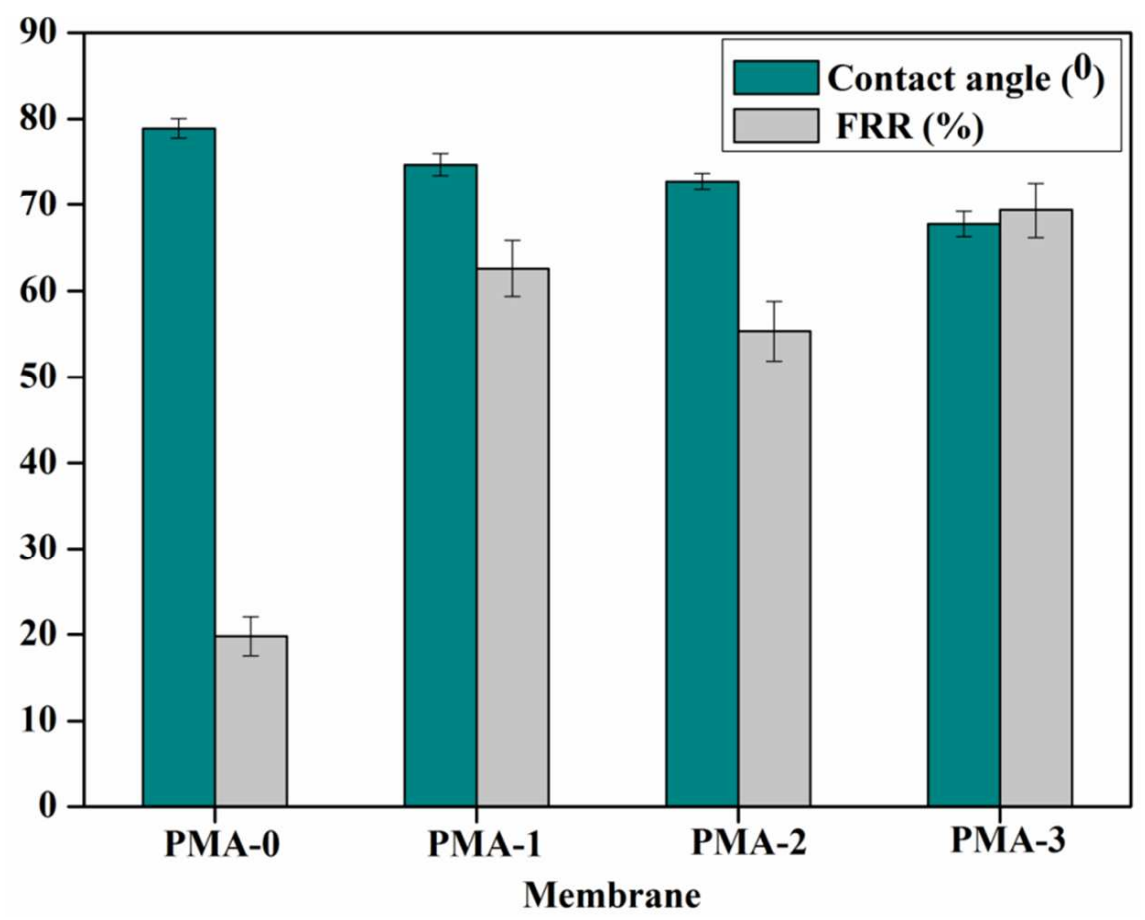

Figure 8 : The contact angle and flux recovery ratio of the prepared membranes 


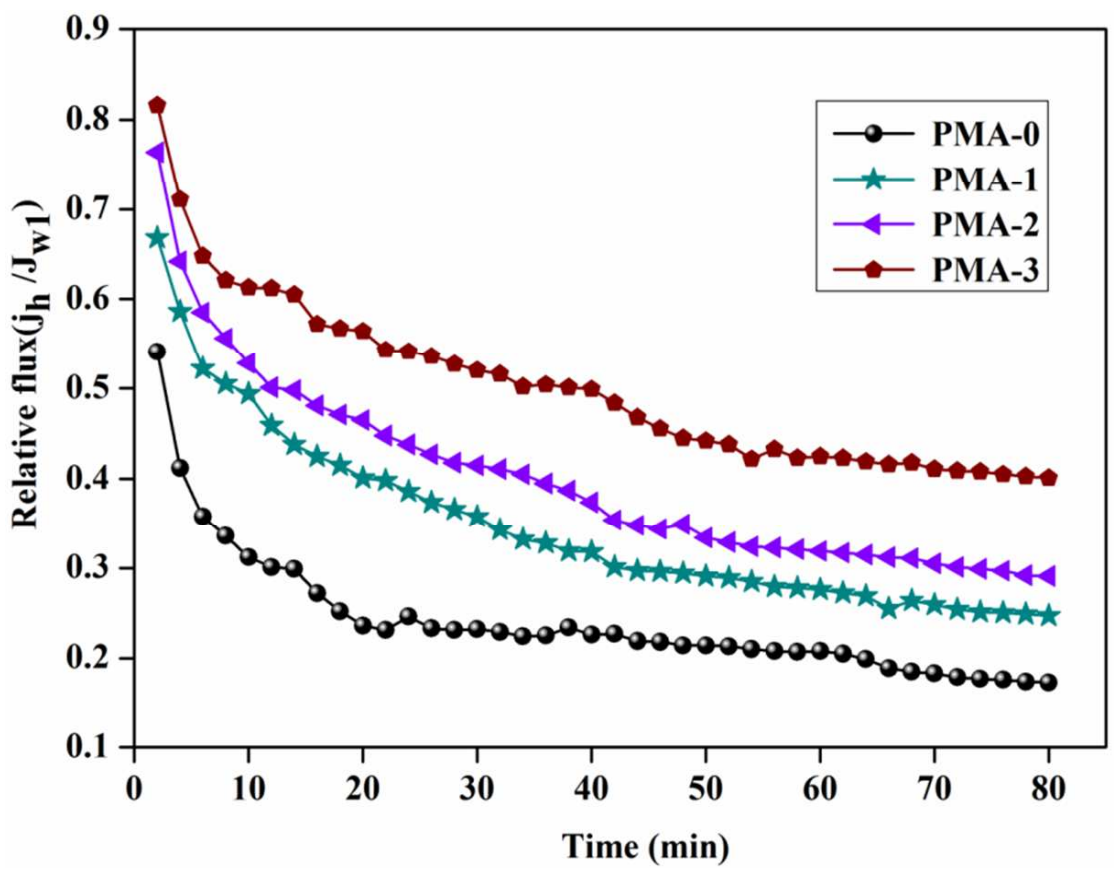

Figure 9 : Flux ratio during the HA solution filtration 


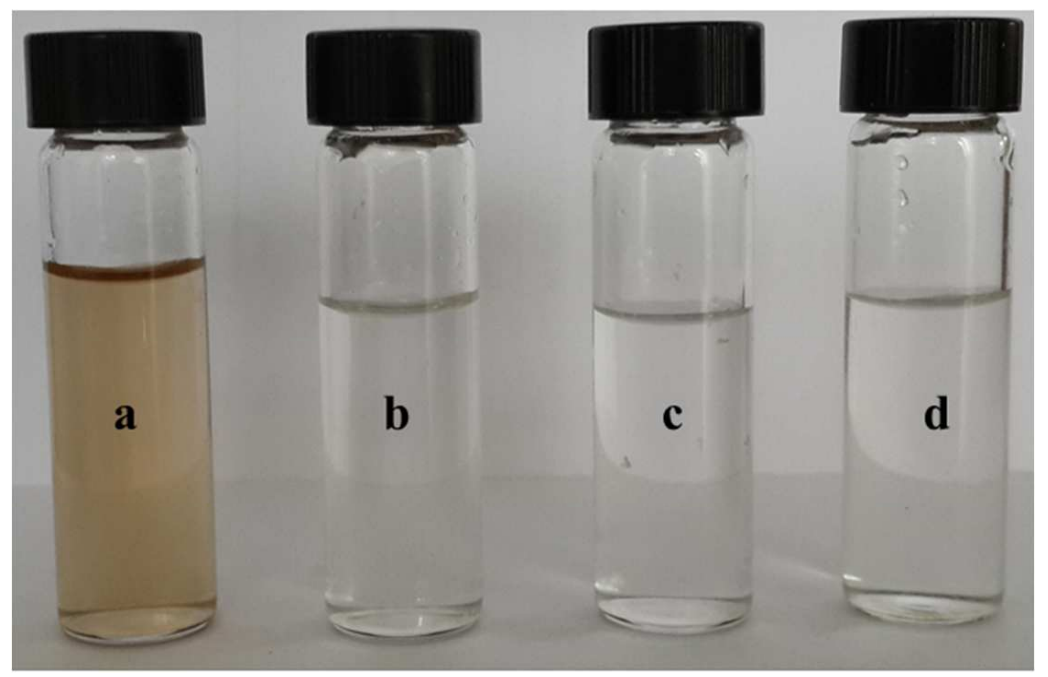

Figure 10 : Photographic image of (a) feed HA solution and b, c and d are the permeate of PMA1, PMA-2 and PMA-3 membranes. 


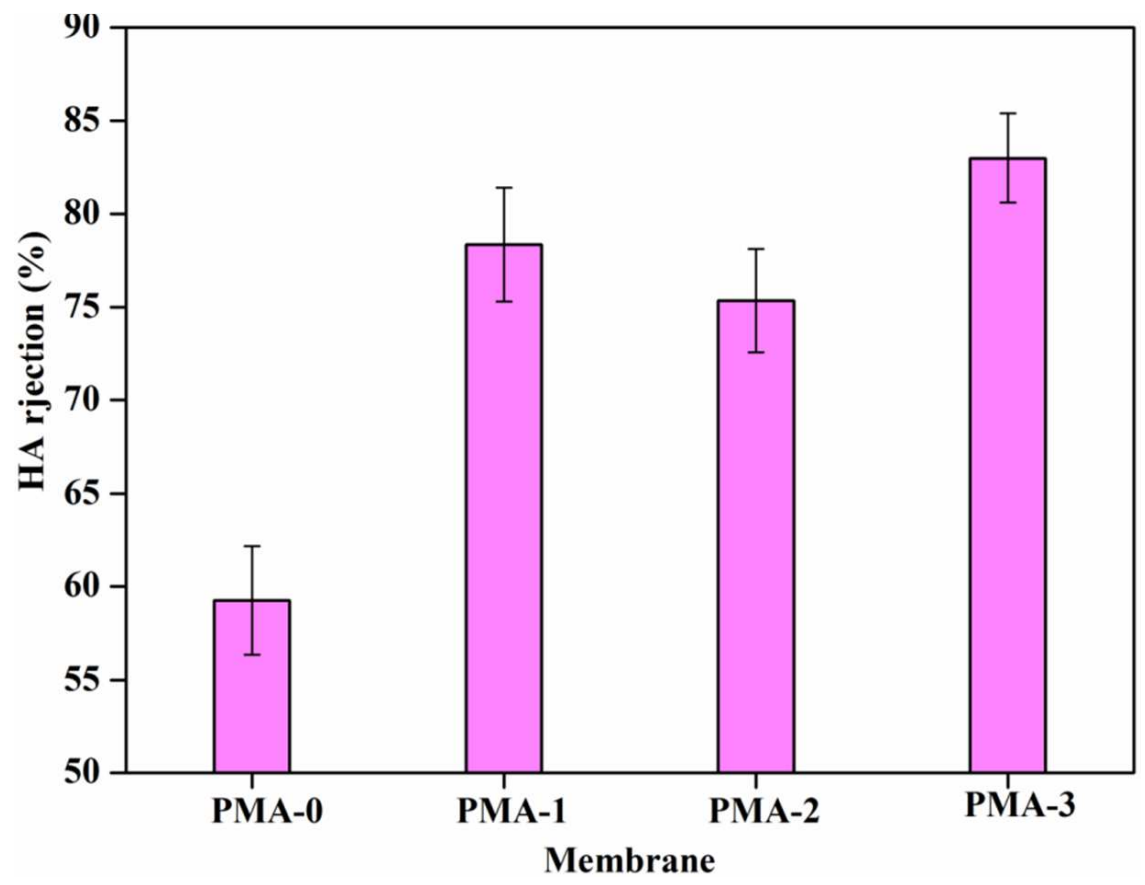

Figure 11 : The HA rejection by prepared membranes 
Table-1: Composition of casting solution

\begin{tabular}{llllll}
\hline Membrane & Additive & PEI (wt.\%) & NMP (wt.\%) & PVP (wt.\%) & Additive (wt.\%) \\
\hline PMA-0 & - & 18 & 80 & 2.0 & - \\
PMA-1 & Ascorbic acid & 18 & 79 & 2.0 & 1.0 \\
PMA-2 & Maleic acid & 18 & 79 & 2.0 & 1.0 \\
PMA-3 & Citric acid & 18 & 79 & 2.0 & 1.0 \\
\hline
\end{tabular}


Table-2: The properties of the membranes

\begin{tabular}{llllll}
\hline Membrane & $\begin{array}{l}\text { Membrane } \\
\text { thickness }(\mu \mathrm{m})\end{array}$ & $\begin{array}{l}\text { Water uptake } \\
(\%)\end{array}$ & $\begin{array}{l}\text { Viscosity } \\
(\mathrm{mPas})\end{array}$ & $\begin{array}{l}\text { Porosity } \\
(\%)\end{array}$ & $\begin{array}{l}\text { Contact angle } \\
\left({ }^{\circ}\right)\end{array}$ \\
\hline PMA-0 & 121 & 58 & 270 & 38.1 & 79 \\
PMA-1 & 123 & 72 & 490 & 53.5 & 75 \\
PMA-2 & 120 & 69 & 382 & 49.4 & 73 \\
PMA-3 & 122 & 76 & 650 & 58.6 & 68 \\
\hline
\end{tabular}


Table-3 : The roughness parameters of the membranes

\begin{tabular}{llllll}
\hline Membrane & Image surface & Surface area & \multicolumn{3}{c}{ Roughness } \\
\cline { 4 - 6 } & area $\left(\mu \mathrm{m}^{2}\right)$ & Difference $(\%)$ & $\mathrm{Ra}(\mathrm{nm})$ & $\mathrm{Rq}(\mathrm{nm})$ & $\mathrm{Rmax}(\mathrm{nm})$ \\
\hline PMA-0 & 101 & 0.53 & 11.5 & 14.3 & 108 \\
PMA-1 & 101 & 1.45 & 10.4 & 14.0 & 177 \\
PMA-2 & 100 & 0.91 & 6.05 & 7.93 & 102 \\
PMA-3 & 101 & 0.58 & 5.55 & 7.0 & 61.5 \\
\hline
\end{tabular}


Table-04 : Filtration and antifouling performance of the membranes

\begin{tabular}{llllllll}
\hline \multirow{2}{*}{$\begin{array}{l}\text { Membrane } \\
\text { code }\end{array}$} & \multicolumn{3}{l}{ Permeate Flux $\left(\mathbf{L} \mathbf{~ m}^{-\mathbf{2}} \mathbf{h}^{-\mathbf{1}}\right)$} & \multicolumn{5}{c}{ FRR and Fouling recovery (\%) } \\
\cline { 2 - 8 } & $J_{w 1}$ & \multicolumn{1}{c}{$J_{p}$} & $J_{w 2}$ & $F R R$ & $R_{t}$ & $R_{r}$ & $R_{i r}$ \\
\hline PMA-0 & 133.1 & 9.2 & 28.6 & 21.4 & 93.0 & 14.5 & 78.6 \\
PMA-1 & 160.5 & 11.5 & 96.8 & 60.3 & 92.5 & 53.1 & 39.7 \\
PMA-2 & 223.8 & 12.1 & 118.5 & 52.9 & 85.0 & 47.5 & 47.1 \\
PMA-3 & 242.3 & 14.2 & 173.5 & 71.6 & 94.1 & 65.7 & 28.4 \\
\hline
\end{tabular}

